\title{
Back pain, ankylosing spondylitis and social media usage; a descriptive analysis of current activity
}

\author{
Elizabeth Reilly ${ }^{1,2}$ (i) Raj Sengupta ${ }^{1}$ (i)
}

Received: 2 March 2020 / Accepted: 4 May 2020 / Published online: 19 May 2020

(c) The Author(s) 2020

\begin{abstract}
Social media usage by back pain patients is a new and developing area. Analysing patterns of this online activity offers a new way to understand our patients' concerns and behaviour around disease. Large volume data can be evaluated on a scale not feasible through alternative methods. A cross sectional review of specific terms relating to 'back pain' (BP) and 'ankylosing spondylitis' (AS) were tracked internationally on popular websites, blogs and boards over two 3 month periods, in 2016 and 2019. Relevant co-terms were also tracked in these discussions, such as 'exercise', 'medication' and 'doctor'. The size of the current online BP conversation is significant; there were over 100,000 mentions/month across each study period, particularly 'low-' BP. Discussions about AS increased threefold between 2016 and 2019. More discussions took place online at the start of the week, and in the afternoons. Pregnancy, baby and mens' health resources were the most popular sites for BP chats. People posting about AS were mainly female (80\%) and predominantly had an established diagnosis, with health forums hosting more of these discussions than for BP. Exercise was more commonly mentioned in the context of BP, whereas medications were more common in the AS conversations. Analysing online discussions about BP and AS helps to identify themes amongst patients. Some are seeking a diagnosis, support, or treatment information. Understanding the massive scale of online conversations could help clinicians adopt targeted approaches to increase patient identification, meet patient concerns better, and optimise engagement.
\end{abstract}

Keywords Ankylosing spondylitis $\cdot$ Back pain $\cdot$ Exercise $\cdot$ Social media $\cdot$ Internet

\section{Introduction}

Health-related social media have seen an explosion in activity over the last few years [1,2]. Patients are more engaged with their healthcare, and they want more detailed information [3]. This helps support the patient-clinician relationship, and optimises compliance. Self-management and exercise are invaluable elements of the management of musculoskeletal conditions and back pain (BP) of all aetiologies

Elizabeth Reilly

elizabethreilly2@nhs.net

Raj Sengupta

rajsengupta@nhs.net

1 Department of Rheumatology, Royal National Hospital for Rheumatic Diseases, Royal United Hospital Bath NHS Foundation Trust, Combe Park, Bath BA1 3NG, UK

2 Department of Pharmacy and Pharmacology, University of Bath, Claverton Down, Bath BA2 7AY, UK
$[4,5]$, although compliance with this is much underestimated $[6,7]$.

Ankylosing Spondylitis (AS), a form of axial spondyloarthritis (SpA), has an estimated mean prevalence of 23.8 per 10,000 in Europe [8]. The peak age of onset is 20-30 years. Such a cohort, therefore, is very relevant for internet-based research as we know that the greatest internet use is amongst younger people [9].

The aim of this work was exploratory, to summarise trends regarding the type of individuals involved in online discussions about $\mathrm{BP}$ and $\mathrm{AS}$, and examine the nature of the conversation at scale, including related discussions concerning exercise and medications.

\section{Methods}

A cross-sectional review of all worldwide online mentions of BP and AS was tracked on popular websites, blogs and boards initially from August to October 2016. A repeat 
search was undertaken over the same months of 2019 to assess how the picture had changed in 3 years. A taxonomy of relevant terms, such as 'back pain' and 'ankylosing spondylitis', was used in appropriate permutations to maximise identification (such as 'backpain'). These were then used in collaboration with additional relevant terms [Appendix 1, Table 1]. The most influential sites, boards and individuals (termed 'reach', defined by the number of posts in the dataset, multiplied by the number of followers of the user or site) were reviewed to explore who may be driving online discussions. Mentions of healthcare professionals, medications and exercise were recorded. Finally, to understand the patients' journey, qualitative coding was used to look at randomised posts for key terms associated with disease stage and symptom duration, as well as established cases of AS.

Data collection was conducted collaboratively between the clinical team and White Swan. White Swan, a registered charity arm of Black Swan, analyses large volumes of data for predictive purposes to improve the health of society, e.g. healthcare organisations and charities [10]. Socialnaut (a social listening app, part of Black Swan's proprietary suits of applications, NEST) and qualitative coding were used by White Swan to identify themes and trends in the discussions. It has over 80 volunteers who carry out work on behalf of the charity and consequently no funding for the project was required. Black Swan provides all technology and intellectual property to White Swan for free and data were gathered via the existing technical integrations between Black Swan and data providers. This includes the full Twitter firehose and all data available from Socialgist (the world's largest social media analytics firm). Ethical approval was not required as the information used was in the public domain and patients were not recruited for participation. Furthermore, no patients' identifiable information was included. All keywords were in English, although the search itself was undertaken globally. Available demographic information and the time of day or week of posts were recorded (accounting for location, and relative to Greenwich Mean Time). Results were compiled by White Swan and fed back to the clinical team.

\section{Results}

\section{Back Pain}

The size of the current online conversation about BP is significant; there were 112,000 mentions/month of BP across the 3-month study period in 2016. This was slightly lower in 2019 at 100,000/month. 'Low' or 'lower back pain' was the most common descriptors at both time points, with a total of 62,760 mentions in 2016 and 35,204 in 2019. Metadata identified a relatively even gender split in BP discussions (52\% male: $47 \%$ female). Twitter was the most frequently used site, hosting $83 \%$ of the conversations in 2016 and $93 \%$ in 2019 . Online boards and forums contributed $14 \%$ of the content, and just 3\% was via blogs. Patient forums (such as patient.co.uk and healthunlocked.com) also saw frequent mentions of BP (5th and 8th, respectively) (Fig. 1, top panel), as well as pregnancy or baby-related sites, (babycentre.com, netmums.com). By 2019, the most popular forum by far was Amazon, largely through product reviews mentioning BP.

The top influencer on Twitter for BP in 2016 (i.e. with the greatest 'reach') was the user MensHealthMag, followed by a number of other similar fitness publications within the top 10. By 2019, health and fitness influencers still made up much out of the top 10. During both 2016 and 2019, mentions of BP were seen more frequently earlier in the week and between midday and $4 \mathrm{pm}$ (Fig. 2, top panel). The weekends generally, Saturdays in particular, saw much less activity.

\section{Ankylosing spondylitis}

In 2016, the international online community saw 1700 mentions/month of 'ankylosing spondylitis'. By 2019, this had risen nearly 3 times to 4398/month. In 2019, axial spondyloarthritis ('axSpA') was also searched for and was only mentioned 2004 times vs 13,195 of AS. Unexpectedly, $80 \%$ of those postings about AS on boards or forums were females compared to an even split in BP discussions.

Similar to that of BP, Twitter was the commonest site for discussions (75\% and 79\%, 2016 and 2019, respectively). In 2016, there was a higher use of 'through boards' (such as Reddit) and health forums for AS (20\% AS vs $14 \%$ BP) (Fig. 1, lower panel), which had reduced substantially to only $2 \%$ by 2019 . The blog use of AS was similar to BP (5\% vs. $3 \%$ ), but baby-related boards were less common. The Spondylitis Association of America was the most popular AS-specific site in 2016, and the NASS Twitter account had the 2 nd greatest reach at both time points. Many influential leaders on Twitter were individuals diagnosed with $\mathrm{SpA}$ or campaigners. The timing of AS posts reflected that for BP, with highest activity in the afternoons and evenings, earlier in the week (Fig. 2, lower panel).

\section{Exercise and medications}

Exercise plays a prominent role in all discussions. At both time points, 'exercise' was consistently mentioned more than 'medications' during BP conversations (2016: 'exercise' 
Fig. 1 Top 10 most popular sites for conversations: 1 st panel-2016: back pain, 2nd panel-2016: Ankylosing Spondylitis, 3rd panel-2019: back pain, 4th panel-2019: Ankylosing Spondylitis

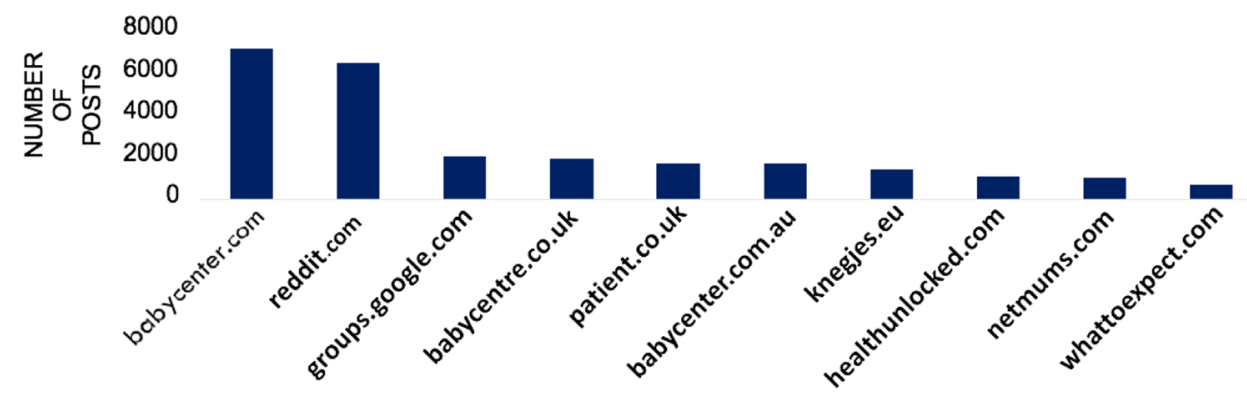

300

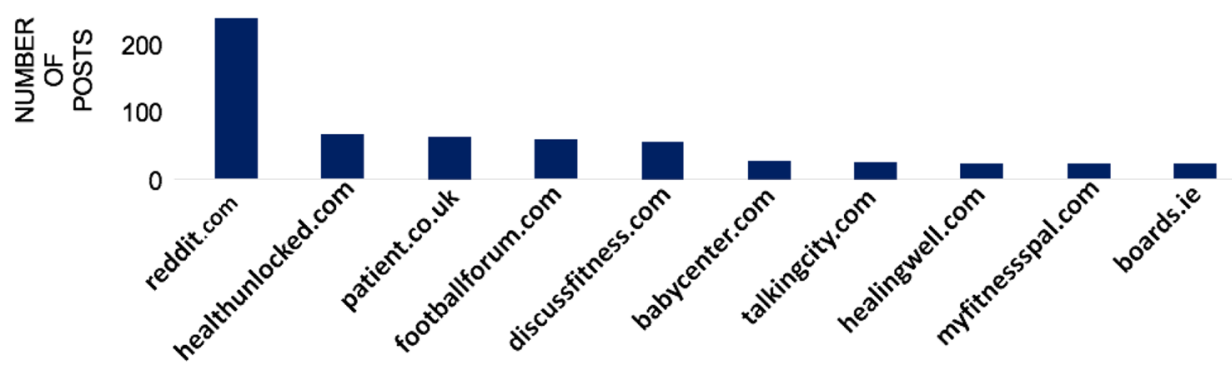

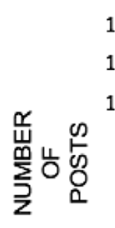

1400

1200

1000
800
600
400
200
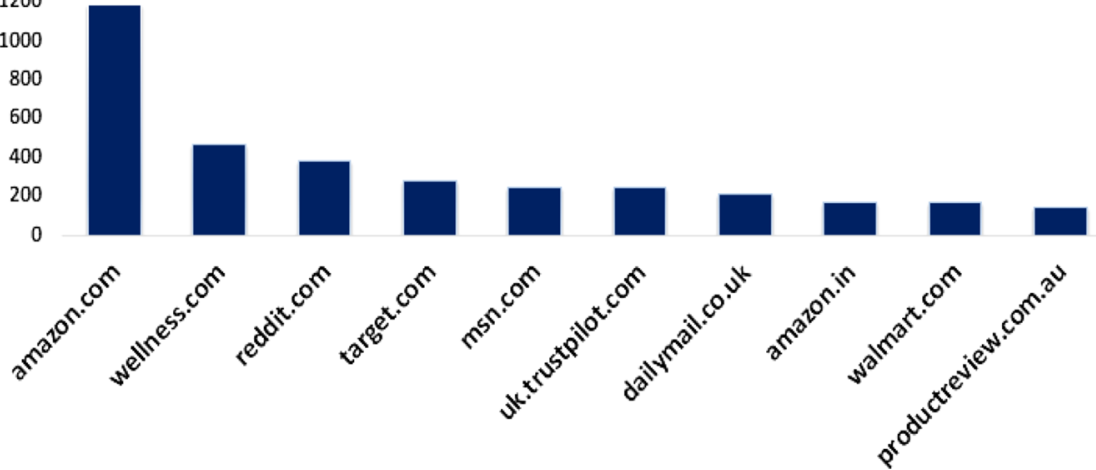

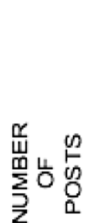

160

140

120

100

80

40

20
0

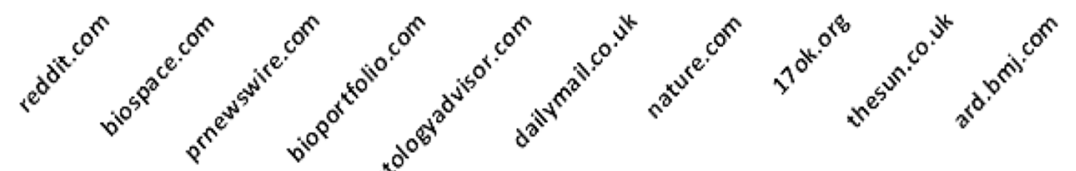



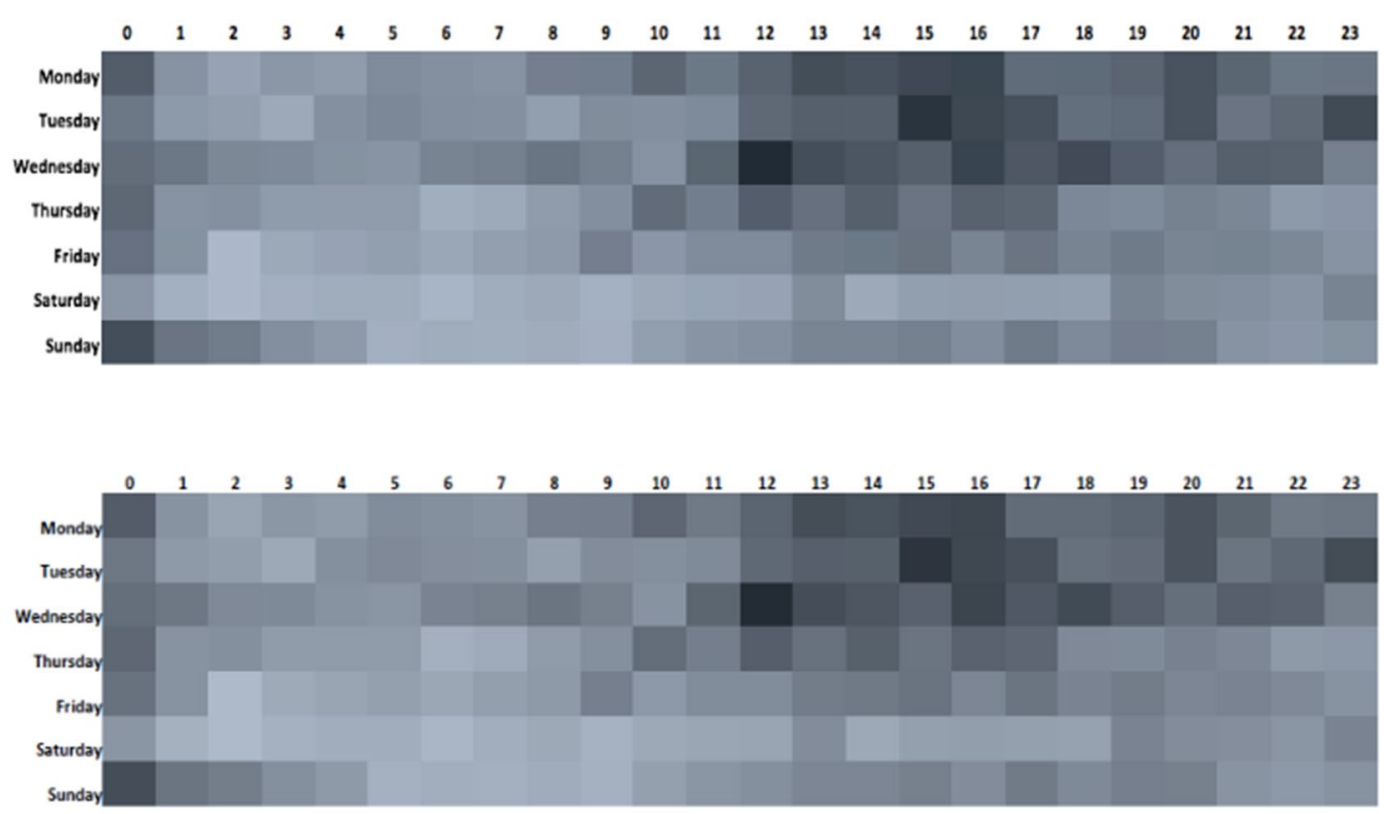

Fig. 2 Timing of online conversations: top panel-discussions regarding back pain, lower panel-discussions regarding Ankylosing Spondylitis [depth of grey scale blocks represents amount of online activity at time points, darker $=$ more mentions of terms in online conversations]

49,993 mentions vs 'medications' 27,306 times, 2019: 18,941 vs 4177). In comparison, 'medications' were more common than 'exercise' in AS discussions (2016: 1018 vs 525, 2019: 1382 vs 700). For BP, yoga was the commonest type of exercise $(4 \%, 13,000$ mentions), and the 7 th most influential resource for AS was a yoga site, DDPYoga.

Non-steroidal anti-inflammatories were the commonest drugs mentioned in 2019, whereas in 2016, it was analgesics, such as paracetamol. Humira was the commonest biologic medication discussed in 2016 (2\% of the total AS conversation), but by 2019 , this was generic adalimumab and Cosentyx (Novartis). Many patients were sharing experiences of treatment.

\section{The patient journey}

Most contributors to the online conversations (71\%) had an existing diagnosis of AS. Twenty-one percent were deemed 'pre-diagnosis' owing to information-seeking behaviour and symptoms. They were commonly seeking or querying a diagnosis of AS by themselves, or others may be suggesting it. Some were expressing frustrations to their doctors for not taking their BP seriously. The remaining $8 \%$ gave indications that suggested a recent AS diagnosis. Patients were presenting to a variety of healthcare professionals, such as ophthalmologists, rheumatologists, GPs and some complementary therapists, such as chiropractors.

\section{Discussion}

AS and BP patients are actively seeking information online through an array of sources with recurring topics of conversation. The conversation around AS is smaller than for $\mathrm{BP}$, which is expected given that $\mathrm{SpA}$ represents $<5 \%$ of BP cases [11]. The AS discussion has grown substantially in 3 years, potentially through increased publicity of the disease in lay publications and the popular media and the work by patient bodies, such as NASS and Versus Arthritis. It must be appreciated though that a broader range of search terms were included in the taxonomy, albeit these made up a small additional proportion of the search. The high proportion of AS mentions by women is an unexpected result, given the 3.8:1 male to female ratio in European AS populations [5]. This very fact, however, may reduce the identification of AS in women and they may consequently be more likely to seek advice online. They could also be searching online on behalf of someone else, which could skew results. Female internet use has increased steadily over the previous two decades, with relatively similar rates of use 
now between genders $[6,12,13]$, further making the trend seen in the AS group surprising. However, when specifically healthcare-related sites are analysed, women rate the usefulness of internet-derived health information more highly than men and also enjoy using the internet more for this purpose [14], perhaps offering an explanation. The high frequency of baby or pregnancy-focussed sites suggests that pregnancyrelated $\mathrm{BP}$ is a common issue. The distribution of postings later in the day may coincide with increased symptoms, such as in mechanical BP. Alternatively, this could reflect a period of reprieve from symptoms, as in inflammatory BP, enabling patients to focus on spending time on the internet. The higher rate of mentions of 'exercise' vs 'doctor' for BP suggests patients understand the importance of this, particularly given the limited role of medications in mechanical BP. Given the importance of exercise in AS, one would have hoped to see more mentions, but as the options for effective medical treatment have increased in recent years, this is not unexpected. Biologic medications are newer treatments and, therefore, patients may be seeking to understand their use. Humira was reported by IMS Health in 2014 as the world's best-selling drug (across indications) [15], so it is not surprising that this is the commonest biologic mentioned in 2016, whilst newer options, such as secukinumab have since become options for treatment. Sharing views on treatments is likely to offer security or validation of patients' own experiences.

There are limitations in this type of study. The level of detail is limited; for example, it is difficult to ascertain the correct usage of medical terms online by the lay public. Using Socialnaut, we have tried to be as comprehensive and inclusive as this methodology allows, but there will be some boards or sites that may not have been included. Search terms were limited to English, which may bias data towards the US and the UK sites. It was not possible to control for the potential unequal global internet provision (Fig. 3) or healthcare systems informing patients' experiences presented online. Understanding wider online healthcare discussions may also offer alternative explanations for some of the patterns seen here. For example, does the timing of posts for BP/AS reflect that is seen in other conditions, or is it due to the diurnal variability in symptoms alone? How does the size of the BP discussion compare to that of other musculoskeletal conditions? This was outside the scope of this work. There was also limited capture of demographic information, such as age, education or other confounders. However, the magnitude of data analysed would not be possible through more traditional study methods and shows trends that can support further work.

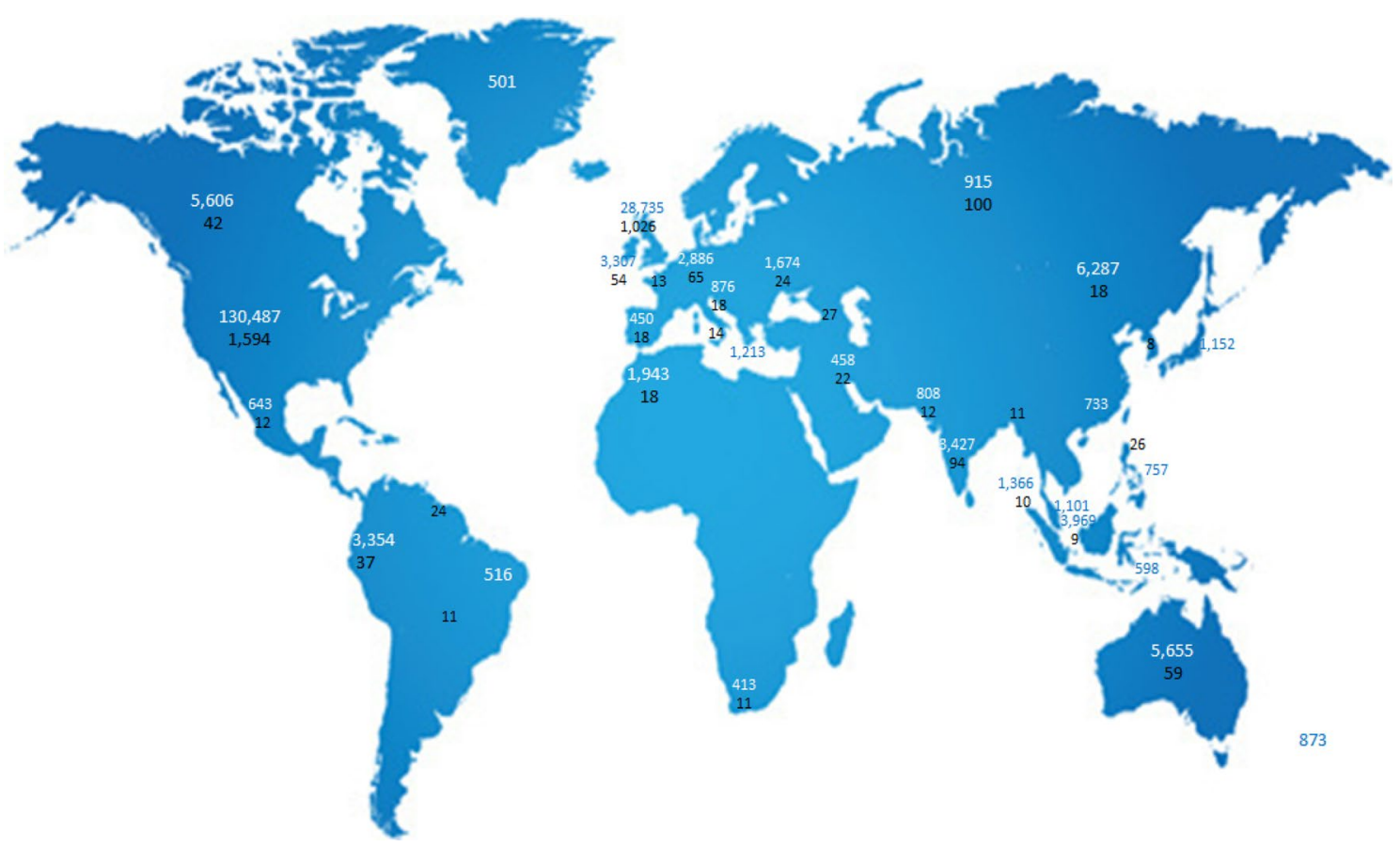

Fig. 3 Worldwide data contribution to analysis, number of posts on topic [blue-back pain, black-AS] 


\section{Conclusion}

This is the first study to utilise big data analysis to describe trends of online discussions of BP and AS, and offers a rich data source relatively untouched for medical research purposes so far. The current online conversation about BP is huge, and that of AS is increasing. Through this analysis, patients appear well-informed, and particularly are seeking diagnoses, and more details on treatment options. Prompt recognition of inflammatory axial symptoms is pivotal in optimising outcomes, particularly given the diagnostic delay in AS, the longest for any rheumatological condition [16]. This sort of data could offer a novel way of flagging potential patients through their online interactions. Targeted patient information could improve patients' understanding of their condition and highlight the importance of exercise. Regular 'hot topic' segments on BP could feature on commonly used sites to engage the public, and encourage presentation to healthcare professionals. The role of campaigners in these discussions emphasises on how potent the personal perspective is for patients. Collaborative work with other healthcare professionals seeing BP patients, such as chiropractors or online influencers, could improve education and facilitate an earlier medical referral. One must, however, be aware of data protection and patient confidentiality when such information is concerned, particularly as technology becomes an increasing part of day-to-day life.

Acknowledgements Miranda Roe, managing director, White Swan, part of the Black Swan company https://www.blackswan.com/white -swan/

IMJE 4 authorship contributions RS had substantial contribution to the design of the work; ER and RS were involved in the acquisition, analysis, and interpretation of data for the work; as well as drafting and critically revising the work for important intellectual content. RS had final approval of the version to be published and ER was in agreement. Both authors agree to be accountable for all aspects of the work in ensuring that questions related to the accuracy or integrity of any part of the work are appropriately investigated and resolved.
Funding No relevant funding support to disclose.

Data availability Data transparency: upon request.Code availability Software application or custom code: upon request from White Swan.

\section{Compliance with ethical standards}

Conflict of interest None of the authors declare any conflicts of interest relevant to this work. ER has been part funded through a research grant by Celgene Corp for unrelated research. RS has received research grants, consultancy and speaker fees from Abbvie, Biogen, Celgene, Lilly, Novartis and UCB.

Ethics approval Ethical approval was not required as the information used was in the public domain and patients were not recruited for participation. No patient identifiable information was recorded or analysed in the study. The work did not fulfil the Health Research Authority's definition of research, as participants were not randomised, there was not change in care for participants, and the results could not be generalised outside of the specific circumstance that was being analysed.

Informed consent Consent to participate and publication: Participants were not required to consent as no recruitment took place to collect data, and data was in the public domain.

Open Access This article is licensed under a Creative Commons Attribution 4.0 International License, which permits use, sharing, adaptation, distribution and reproduction in any medium or format, as long as you give appropriate credit to the original author(s) and the source, provide a link to the Creative Commons licence, and indicate if changes were made. The images or other third party material in this article are included in the article's Creative Commons licence, unless indicated otherwise in a credit line to the material. If material is not included in the article's Creative Commons licence and your intended use is not permitted by statutory regulation or exceeds the permitted use, you will need to obtain permission directly from the copyright holder. To view a copy of this licence, visit http://creativecommons.org/licenses/by/4.0/.

\section{Appendix 1 Search terms}

See Table 1.

Table 1 Additional search terms from 2019 re- analysis indicated with *

\begin{tabular}{ll}
\hline $\begin{array}{l}\text { Back pain and other symptoms } \\
\text { Ankylosing spondylitis }\end{array}$ & $\begin{array}{c}\text { Back pain, pain in my back, back stiffness*, joint pain*, joint stiffness*, uveitis* } \\
\text { Ankylosing spondylitis, ankylosingspondylitis, AS, chronic pain, chronic pain, AS symptoms*, symptoms of } \\
\text { AS*, sign of AS*, spine inflammation*, inflammation of the spine* }\end{array}$ \\
Axial SPA & Axial Spondyloarthritis*, Axial Spa* \\
NSAIDs & Brufen, naproxen, diclofenac, indomethacin, meloxicam, etodolac, celebrex, arcoxia, Non-steroidal anti- \\
& inflammatory drugs (NSAIDS)* \\
Painkillers & Paracetamol, cocodamol, codydramol, tramadol, coproxamol, morphine, painkillers* \\
DMARDs & Methotrexate, sulphasalazine, leflunomide, Disease-modifying drugs (DMARDs)* \\
Biologics & Humira, adalimumab, Enbrel, etanercept, simponi, golimumab, remicade, infliximab, cimzia, certolizumab, \\
& cosentyx, secukinumab \\
Exercise & Exercise, exercises, yoga, pilates, gym
\end{tabular}




\section{References}

1. Smailhodzic E, Hooijsma W, Boonstra A, Langley DJ (2016) Social media use in healthcare: a systematic review of effects on patients and on their relationship with healthcare professionals. BMC Health Serv Res 16(1):442

2. Hawn C (2009) Report from the field: take two aspirin and tweet me in the morning: how twitter, facebook, and other social media are reshaping health care. Health Aff 28(2):361-368

3. Rupert DJ, Moultrie RR, Read JG, Amoozegar JB, Bornkessel AS, O'Donoghue AC et al (2014) Perceived healthcare provider reactions to patient and caregiver use of online health communities. Patient Educ Couns 96(3):320-326

4. Zochling J, van der Heijde D, Burgos-Vargas R, Collantes E, Davis JC, Dijkmans B et al (2006) ASAS/EULAR recommendations for the management of ankylosing spondylitis. Ann Rheum Dis 65(4):442-452

5. Santos H, Brophy S, Calin A (1998) Exercise in ankylosing spondylitis: how much is optimum? J Rheumatol 25(11):2156-2160

6. Passalent LA, Soever L, O'Shea FD, Inman RD (2010) Exercise in ankylosing spondylitis: discrepancies between recommendations and reality. J Rheumatol. 37(4):835-841

7. Falkenbach A (2003) Disability motivates patients with ankylosing spondylitis for more frequent physical exercise. Arch Phys Med Rehabil 84(3 SUPPL. 1):382-383

8. Dean LE, Jones GT, Macdonald AG, Downham C, Sturrock RD, Macfarlane GJ (2014) Global prevalence of ankylosing spondylitis. Rheumatol 53(4):650-657
9. Hills P, Argyle M (2003) Uses of the internet and their relationships with individual differences in personality. Comput Hum Behav 19(1):59-70

10. Black Swan (2019) Our story. Available at: https://www.black swan.com/our-story/. Accessed 18 May 2020

11. Underwood MR, Dawes $P$ (1995 Nov) Inflammatory back pain in primary care. Br J Rheumatol 34(11):1074-1077

12. Fang X, Yen DC (2006) Demographics and behavior of Internet users in China. Technol Soc 28(3):363-387

13. National Telecommunications and Information Administration (2002) A nation online : how Americans are expanding their use of the internet. Popul. National Telecommunications and Information Administration, Washingtona

14. Bidmon S, Terlutter R (2015) Gender differences in searching for health information on the internet and the virtual patient-physician relationship in germany: exploratory results on how men and women differ and why. J Med Internet Res 17:1-23

15. IMS Health (2017) Top-Line Market Data, 2015 knoema.com. https://knoema.com/IMSH2014/ims-health-top-line-market-data2015? global-market=1000020-humira. Accessed 24 Apr 2017.

16. Dincer U, Cakar E, Kiralp MZ, Dursun H (2008) Diagnosis delay in patients with ankylosing spondylitis: possible reasons and proposals for new diagnostic criteria. Clin Rheumatol 27(4):457-462. https://doi.org/10.1007/s10067-007-0727-6

Publisher's Note Springer Nature remains neutral with regard to jurisdictional claims in published maps and institutional affiliations. 